\title{
Air cooling analysis and design of impacted flexible actuator's servo controller based on PLECS
}

\author{
Mingjun Zhu, Liqun Xia, Yixue Hu, Wei Zhang, Duohong Ji and Xin Song \\ Flight Automatic Control Research Institute, 710129Dianzi Yi Road Xi'an ShaanxiChina
}

\begin{abstract}
At present, SUAV (small unmanned aerial vehicle) is developing with small shape, high dynamic performance and distributed structure. Meanwhile the power by wire, which can replace traditional hydraulic system to lighten weight and improve reliability, is important developing direction of actuator technology in future. When a plane which applies power by wire is doing high-g routine, the power devices' loss is giant because of the high power. Thus it is necessary to design cooling structure to carry out heat from controller inner. To avoid over design and analyze more exactly, this paper introduces a method based on MATLAB and PLECS union Simulink to calculate controller's loss. By power devices' thermal resistance and working temperature referred from products manual, it is possible to define cooler's size. Then we can achieve wind pressure and flow characteristic curve, and select the cooling fan. Compared with theory calculation, this method can achieve exact controller loss in different working conditions and take effects which influenced by temperature in consideration, by what we can avoid cooling structure's over design.
\end{abstract}

\section{Introduction}

At present, SUAV (small unmanned aerial vehicle)is developing with small shape, high dynamic performance and distributed structure. While aerospace servo actuator technology is approaching to power by wire, high temperature and pressure resistant actuator or combination with advanced material. Future actuator will have such features: high power -weight ratio, high reliability and long server life. In this background, distributed impacted flexible actuator is come up, whose drive is not hydraulic but electric power and controller has obvious optimization in volume, power-weight ratio, reliability and serve life. However, controller's cooler design is far more difficult.

In controller, IGBT power module is major energy loss source, if its cooling design has limitation, the power components' juction temperature will rise up immediately and out of allowance range, which decreases of performance and reliability, and even leads to components' burning. Thus, the cooling design of impacted flexible actuator's controller is extremely important.

The traditional method to calculate the size of heat sink is as followed, formula is used to calculate the conduction loss and switching loss on the most harsh working conditions, then calculate the total loss, the size of heat sink is determined according to this value. this paper presents a method of co-simulation for loss calculation of power devices, and then the maximum resistance is used to determine the size of heat sink. The loss of power devices is also obtained in different working conditions, the value calculated by this method is more close to the real value, it can also avoid the over design of heat sink.

\section{Loss analysis of controller}

The diagram of impacted flexible actuator discussed by this paper is shown in Figure 1. It consists of high speed wet motor, hydraulic pump, check valves, stress sensors, relief valves, SOVs (solenoid operation valve), anticavitation valves, MSV (mode selected valve) and actuator ram. The controller is used to realize the motor power supply and transform voltage from $\mathrm{DC}$ to $\mathrm{AC}$, to achieve the closed-loop control of motor current loop and speed loop, and to realize over-voltage, over-current, over-temperature protection functions. Controller power supply voltage is $270 \mathrm{~V}$ and $28 \mathrm{~V}$, rated current is $60 \mathrm{~A}$. Because of the design requirement of the actuator power to weight ratio, cooling design is the key technology in this project.

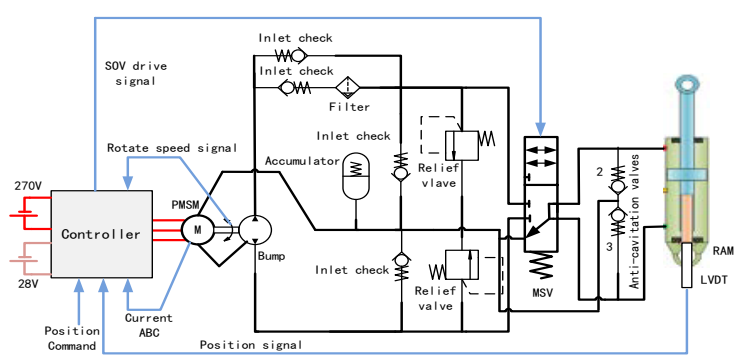

Figure 1. Diagram of impacted flexible actuator. 


\subsection{Switching loss}

Switching loss includes turn-on loss and shut-off loss. Turn-on loss refers to the non-ideal switches in open state, voltage is not immediately drops to zero, but there is a decline in time, at the same time, current also not immediately rises to the load current, there is a rising time. During this period of time, the current and voltage of the switch tube have an overlapping area, which will produce the loss. The reason of producing turn-off loss is similar to the turn-on loss. .

$$
\begin{gathered}
P_{s w-T r}=f_{s}\left(E_{\text {on }}+E_{\text {off }}\right) \frac{\sqrt{2}}{\pi}\left(\frac{I_{\text {out }}}{I_{\text {rated }}}\right)^{K_{s w T r-1}}\left(\frac{V_{c c}}{V_{\text {rated }}}\right)^{K_{s w T r-r}} \\
{\left[1+K_{s w T r-T}\left(125^{\circ} C-T_{j-T r}\right)\right]} \\
P_{s w-D}=f_{s} E_{r r} \frac{\sqrt{2}}{\pi}\left(\frac{I_{\text {out }}}{I_{\text {rated }}}\right)^{K_{s w T r-I}}\left(\frac{V_{c c}}{V_{\text {rated }}}\right)^{K_{s w T-V}} \\
{\left[1+K_{s w D-T}\left(125^{\circ} C-T_{j-D}\right)\right]}
\end{gathered}
$$

Among them:

$$
\begin{aligned}
& P_{S W-T T} \quad \text { IGBT's switching loss; } \\
& f_{s} \quad \text { Carrier frequency; } \\
& E_{\text {on }} / E_{\text {off }} \quad \text { IGBT's single impulse turn-on and shut-off } \\
& \text { on } E_{\text {off }} \text { loss in rated condition; } \\
& I_{\text {rated }} \quad \text { Reference current; } \\
& V_{c c} \quad \text { Bus voltage; } \\
& V_{\text {rated }} \quad \text { Reference voltage; } \\
& K \quad \text { Coefficient which current amplitude influences } \\
& K_{S W T Y-I} \quad P_{S W-T r} \\
& K \quad \text { Coefficient which bus voltage influences } \\
& \begin{array}{ll} 
& P_{S W-T r} \\
& \text { Coefficient which temperature influences }
\end{array} \\
& K_{s w T r-T} \quad P_{S W-T r} \\
& P_{S w-D} \quad \text { Fly-wheel diode's switching loss; } \\
& E_{r r} \quad \text { Fly-wheel diode's single impulse conduction } \\
& \text { and shut-off loss in rated condition; } \\
& K_{s w D-I} \quad P_{S W-D} ; \\
& \begin{array}{ll}
K_{s w D-V} & \text { Coefficie } \\
P_{S W-D}
\end{array} \\
& \begin{array}{ll}
K_{S w D-T} & \text { Coefficic } \\
& P_{S W-D}
\end{array}
\end{aligned}
$$

\begin{tabular}{|c|c|}
\hline$P_{\text {cond }-\mathrm{Tr}}$ & IGBT's conduction loss; \\
\hline$I_{\text {out }}$ & Actual output of current virtual value; \\
\hline$M$ & $\begin{array}{l}\text { PWM's modulation degree(phase voltage } \\
\text { peak value divides half bus voltage); }\end{array}$ \\
\hline$\psi$ & $\begin{array}{l}\text { Phase degree between actual current vector } \\
\text { and actual voltage vector; }\end{array}$ \\
\hline$V_{c e-25}$ & $\begin{array}{l}\text { IGBT's rated conduction voltage in } 25 \\
\text { degree centigrade; }\end{array}$ \\
\hline$T_{j-T r}$ & IGBT's actual juction temperature; \\
\hline$R_{c e-25}$ & $\begin{array}{l}\text { IGBT's rated conduction resistance in } 25 \\
\text { degree centigrade; }\end{array}$ \\
\hline$K_{r-T r}$ & $\begin{array}{l}\text { Coefficient which temperature influences } \\
\text { IGBT's conduction resistance; }\end{array}$ \\
\hline$K_{V-T r}$ & $\begin{array}{l}\text { Coefficient which temperature influences } \\
\text { IGBT's conduction voltage; }\end{array}$ \\
\hline$P_{\text {cond }-D}$ & Fly-wheel diode's conduction loss; \\
\hline$V_{F-25}$ & $\begin{array}{l}\text { Fly-wheel diode's rated conduction voltage } \\
\text { in } 25 \text {; }\end{array}$ \\
\hline$K_{V-D}$ & $\begin{array}{l}\text { Coefficient which temperature influences } \\
\text { conduction voltage; }\end{array}$ \\
\hline$T_{j-D}$ & $\begin{array}{l}\text { Fly-wheel diode's actual juction } \\
\text { temperature; }\end{array}$ \\
\hline$R_{F-25}$ & $\begin{array}{l}\text { Fly-wheel diode's rated conduction } \\
\text { resistance in } 25 \text { degree centigrade; }\end{array}$ \\
\hline$K_{r-D}$ & $\begin{array}{l}\text { Coefficient which temperature influences } \\
\text { Fly-wheel diode's conduction resistance }\end{array}$ \\
\hline
\end{tabular}

\subsection{Conduction loss}

When switch is in conducting state, there is conduction voltage at the two ends of the switch tube, because of this reason, the loss produced by this switch tube is called conduction loss. The loss is proportional to voltage, time and the square of the current. And the value is also related to temperature.

$$
\begin{aligned}
P_{\text {cond }-T r}= & I_{\text {out }} \sqrt{2}\left(\frac{1}{2 \pi}+\frac{M \cos \psi}{8}\right)\left[V_{c e-25}+K_{v-t r}\left(T_{j-T r}\right.\right. \\
& \left.\left.-25^{\circ} C\right)\right]+2 I_{\text {out }}^{2}\left(\frac{1}{8}+\frac{M \cos \psi}{3 \pi}\right)\left[R_{c e-25}\right. \\
& \left.+K_{r-T r}\left(T_{j-T r}-25^{\circ} \mathrm{C}\right)\right]
\end{aligned}
$$

$$
\begin{aligned}
P_{\text {cond }-D}= & I_{\text {out }} \sqrt{2}\left(\frac{1}{2 \pi}-\frac{M \cos \psi}{8}\right)\left[V_{F-25}+K_{v-D}\left(T_{j-D}\right.\right. \\
& \left.\left.-25^{\circ} C\right)\right]+2 I_{\text {out }}^{2}\left(\frac{1}{8}-\frac{M \cos \psi}{3 \pi}\right)\left[R_{F-25}\right. \\
& \left.+K_{r-D}\left(T_{j-D}-25^{\circ} C\right)\right]
\end{aligned}
$$

Among them:

\section{Inverter loss analysis based on PLECS}

In PLECS emulation, the values of power model's switching loss andstate loss are modified, the simulation model can be used calculate the loss of power module at every moment in the working state of the device. At the same time, the external dissipation structure of power model can be designed, and the influence of temperature on the loss of power model is considered. The steps of simulation analysis are as follows. Firstly, according to the working condition of the controller, including cooling loop model, simulation is designed, and then according to the data sheet of power model, all kinds of loss parameters can be fond and set up. Finally simulation analysis is done to get the simulation results.

\subsection{Building emulation model}

The tested power module is applied to a large power motor controller, and the power module is used as the inverter to complete the DC to AC conversion function. So the simulation model needs to include the motor control algorithm model, three phase inverter model and motor model, as shown in Figure 4. The inverter model is built by the module in PLECS, which is because the power module model of PLECS contains thermal analysis function, and the model of the motor is used in PLECS. 
The control strategy model is completed by the mathematical model of MATLAB, it needs to realize the closed-loop control of motor current and speed loop, which is used to drive the motor to always work in the maximum power state.

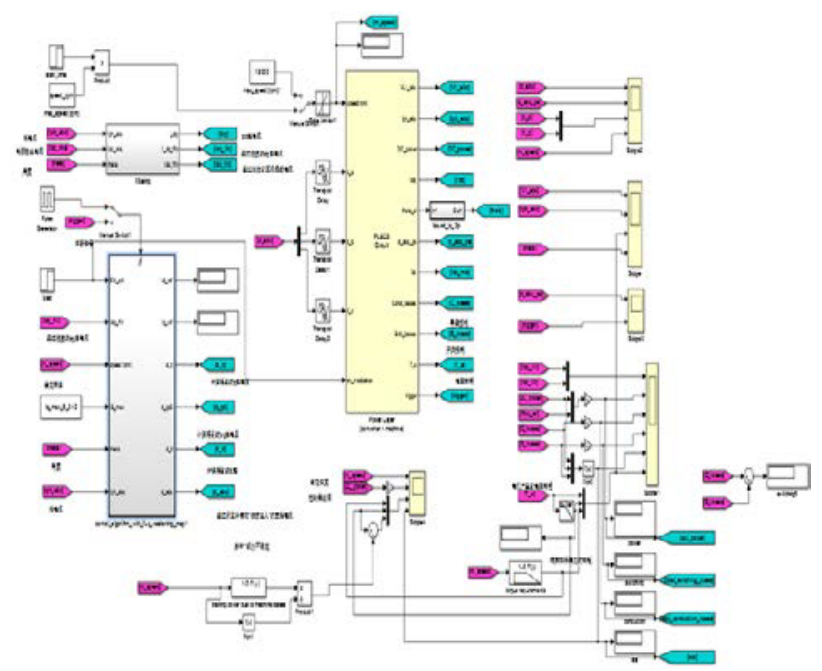

Figure 2. Emulation model for controller loss.

PLECS in the calculation of power device heat dissipation performance is more prominent, and it can be combined with MATLAB simulation, in this paper a single bridge of the power device is built in Figure 5. The driving signal is obtained by MATLAB simulation module, the dead time is generated through the simulation module. The purple area is heat loss calculation region. Several modules in the lower right corner is the standard module for calculating power device conduction loss and switching loss.

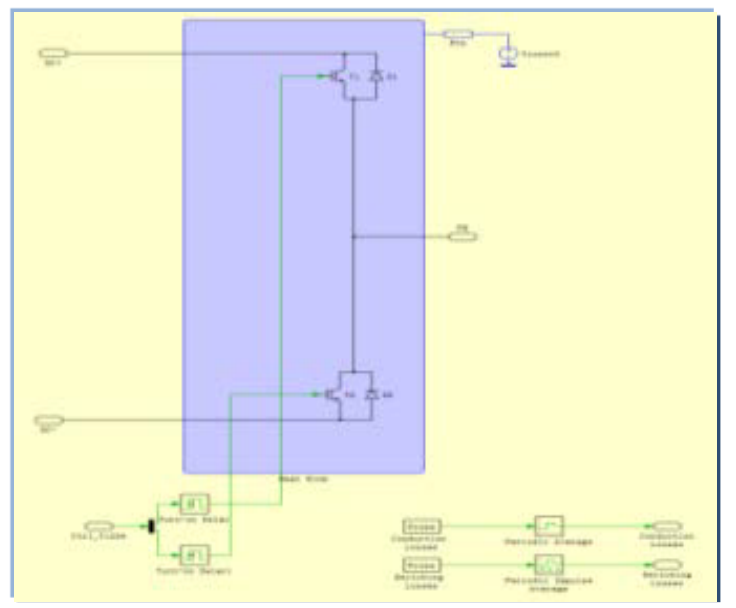

Figure 3. Emulation model for inverter loss.

\subsection{Power components loss parameters configuration}

In loss of power device, conduction and switching losses accounte for most of the total loss and other loss is negligible. temperature and current change lead to the change of this two kinds of losses. With data sheet, switching loss and conduction loss curves can be obtained as shown in Figure 4.

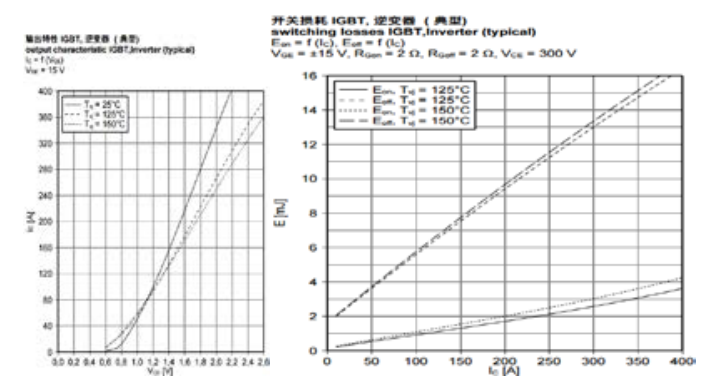

Figure 4. IGBT switching loss and on-state loss curve.

According to the curves shown in Figure 4, using the traditional method of tracing points, the values ofIGBT's and parallel diode's switching loss and condition loss can be obtained at different working condition points. Loss curves at different temperature are shown in Figure 5 and Figure 6.

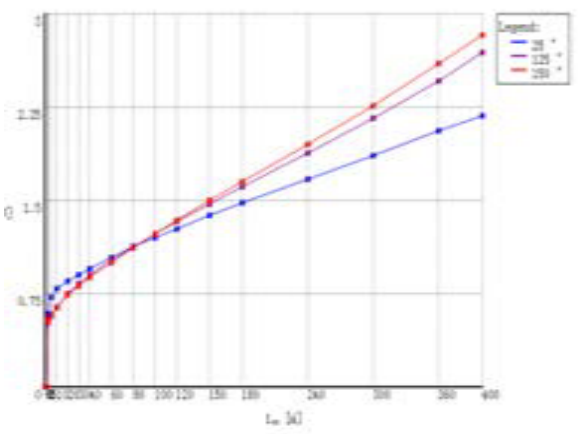

Figure 5. IGBT confuction loss curve.

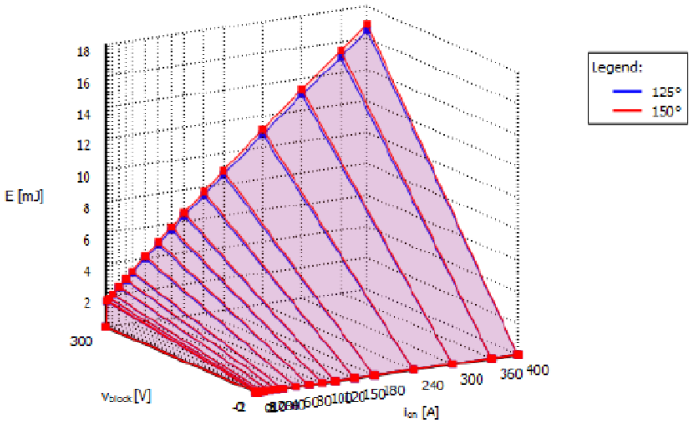

Figure 6. IGBT shut-off loss curve.

\subsection{Emulation and analysis results}

Through the control strategy, it can ensure that the motor always works in the maximum load state, the motor speed is from $0 \mathrm{rpm}$ up to maximum speed. When motor reaches the maximum speed, reduce the current amplitude to reduce torque. Look up the loss of power device in different operating conditions, and then determine the maximum loss value, which is used to calculate the subsequent heat dissipation structure parameter.

Through the simulation analysis, the results are obtained as shown in Figure 9, considering the theoretical analysis, the conduction loss is proportional to motor current, having nothing to do with the switching frequency, and switching loss is not only proportional to the current amplitude but also associated with the switching frequency. The motor works at the maximum 
power point when motor speed runs from $0 \mathrm{rpm}$ to maximum speed. After speed reach the maximum value, motor's electromagnetic torque will decline and current amplitude will decrease, so the total loss of power module will also decline. The loss of 3 up bridge arms is $207 \mathrm{~W}$, so the total loss is $414 \mathrm{~W}$. When the motor's actual rotate speed achieves given rotate speed, switching loss and conduction loss decrease because of inverter current being small. The emulation results are shown in Figure 7.

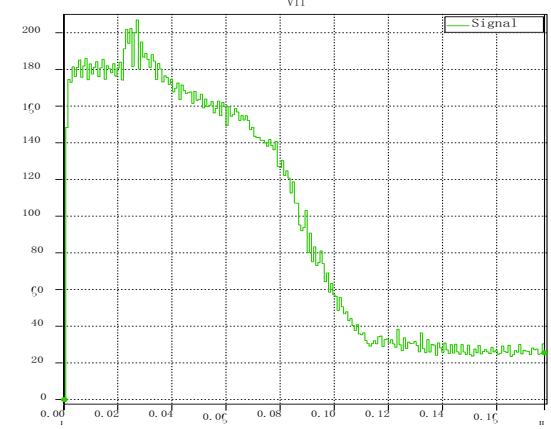

Figure 7. Loss curve of inverter.

\section{Design of inverter's heat sink}

In the actual use of heat sink, there are many factors affecting the thermal resistance. In the choice of heat sink's size, the max needed thermal resistance is used to determine the heat sink's structure, and also other factors are considered as follow, like stricter, cost, wind pressure, cooling effect and so on. The thinner fin the better cooling is, but while its effect is better, it is more difficult and cost more. So far, there is no accurate mathematical formula to calculate the thermal resistance of the heat sink, the size of this heat sink used in this project is shown in Figure 8.

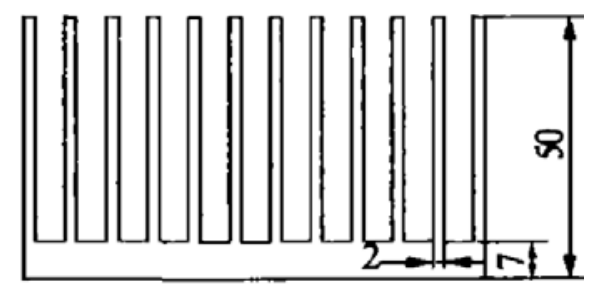

Figure 8. Cooler's Size.

We can calculate the maximum heat sink required thermal resistance to determine the size of heat sink. When the thermal resistance of actual heat sink is less than the required maximum thermal resistance, even if the controller works in the most harsh environment, the controller's temperature will not exceed allowable working temperature of power device. The maximum heating amount obtained by simulation is $414 \mathrm{~W}$. Through look up the data sheet, we find the follow information, IGBT's highest acceptable working temperature is Centigrade 150 degrees, thermal resistance which from IGBT's tablet core to shell is: $\mathrm{RIthCH}=0.085 \mathrm{~K} / \mathrm{W}$. Which from IGBT's shell to cooler is: RIthJC $=0.25 \mathrm{~K} / \mathrm{W}$. Which from diode's tablet core to shell is: $\mathrm{RDthCH}=0.15 \mathrm{~K} / \mathrm{W}$, Which from diode's shell to cooler is: $\mathrm{RD}$ thJC $=0.45 \mathrm{~K} / \mathrm{W}$.
According to thermal resistance values above, the thermal resistance from power module to cooler's surface is:

$$
\begin{aligned}
R_{I} & =\frac{1}{6}\left(R_{I t h J C}+R_{I t h C H}\right) / /\left(R_{D t h J C}+R_{D t h C H}\right) \\
& =0.0358 K / W
\end{aligned}
$$

Suppose:

1. air temperature in controller box is worst to Centigrade 70 degrees

2. TIjuction $\geqslant 0.9 \mathrm{~T} \operatorname{Imax}=135^{\circ} \mathrm{C}$.

So we can get:

$$
R_{H} \leq 0.12 K / W
$$

According to conclusion above, when thermal resistance of cooler selected is smaller than $0.12 \mathrm{~K} / \mathrm{W}$, the design can meet cooling requirement. The cooler's size is $180 \mathrm{~mm} \times 100 \mathrm{~mm} \times 50 \mathrm{~mm}$, which has 25 cooling air ducts, and every fin's length is $43 \mathrm{~mm}$, the distance between two fin is $5 \mathrm{~mm}$.

\subsection{Fan's selection and working point's check}

Traditional cooling technology, including air cooling, water cooling or oil cooling, has different application occasion. When used in aircraft servo actuator system, forced air cooling is the best controller cooling style based on weight limit. This paper selects 4 fans produced by SANYO, whose type is 9CRD0412P5J03. The fans work in constant power, which means when wind pressure produced by fan increases, the wind flow rate will decrease. Thus the fans' working point should be made sure for cooling efficiency.

\subsection{Wind resistance characteristic of cooler}

Suppose the fans and the cooler selected can bring total heat out of controller box, then based on heat balance equation we can get:

$$
\begin{aligned}
L & =\frac{Q}{\rho C_{p}\left(t_{0}-t_{i}\right)}=\frac{414}{1.13 * 1.005 *(70-50)} \\
& =1.09 \mathrm{~m}^{3} / \mathrm{min}
\end{aligned}
$$

$L \quad$ Cold air flow;

$Q \quad$ Loss of controller;

$\rho \quad$ Air density;

$C_{p} \quad$ Air specific heat;

$t_{i} \quad$ In port temperature of air;

$t_{0} \quad$ Out port temperature of air.

To ensure reliability of cooling, there is additional $20 \%$ cooling margin needed, thus:

$$
L_{\min } \geq 1.2 * L=1.31 \mathrm{~m}^{3} / \mathrm{min}
$$

So the flow every fan is required to produced is not less than $0.328 \mathrm{~m} 3 / \mathrm{min}$. 
When flowing, the air duct, whose length is $\mathrm{y}$, has wind resistance of:

$$
\begin{aligned}
R & =\frac{\lambda}{4 R_{s}} \frac{v^{2}}{2} \rho y=\frac{0.022}{4 \times 2.24 \times 10^{-3}} \frac{v^{2}}{2} \times 1.13 \times 0.1 \\
& =0.139 v^{2}
\end{aligned}
$$

$R \quad$ Resistance of cooler's air duct;

$\lambda \quad$ Coefficient of frictional resistance;

$\rho \quad$ Air density;

$v \quad$ Mean velocity of air in air duct;

$R_{S} \quad$ The equivalent hydraulic radius of air duct;

$y \quad$ Length of air duct;

The cooler's total width is $180 \mathrm{~mm}$, which have 25 air ducts. The relationship between cooler flow and mean velocity of air in air duct is that:

$$
v=\frac{L}{60 \times 25 a b}=\frac{L}{60 \times 25 \times 5 \times 43}=3.1 L
$$

Combine equation (10) into equation (9), we can get:

$$
R=0.139 v^{2}=0.139 \times(3.1 L)^{2}=1.336 L^{2}
$$

When fans make air flows in, wind pressure must achieve to meet cooling requirement.

$$
R_{\min } \geq 1.336 L_{\min }{ }^{2}=2.29 P a
$$

By referring the fan's working characteristic curve as shown in Figure 9, it is obvious that when drive PWM's (fan's) duty cycle is $50 \%$, the air flow is able to get, while fan's wind pressure is $45 \mathrm{~Pa}$, which meets the requirement.

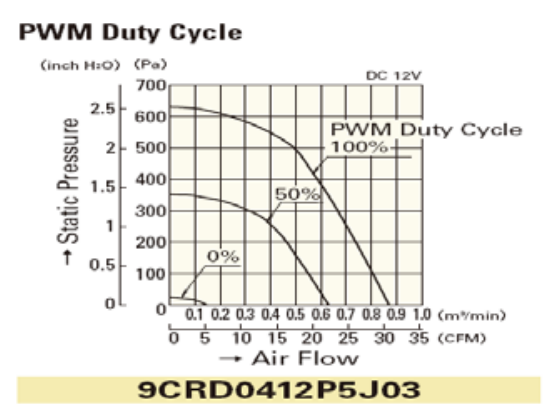

Figure 9. Working characteristic curve of fan.

According to method put forward by this paper, the cooling structure is as following:

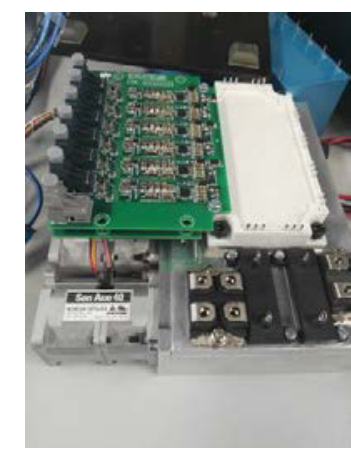

Figure 10. Picture of cooler structure.

\section{Conclusion}

This paper introduces a compact smart actuator structure, in order to improve the controller's power to weight ratio, we need ensure the performance of heat sink, and reduce the size of heat sink as possible. Then it introduces the formula of power device loss to obtain the power device loss factors. Finally, it presents a method of calculating the total loss of power device based on PLECS and MATLAB, according to this method, switching loss, conduction loss and total loss curves are obtained, they are used to determine the size of heat sink, and select the fan. At the last checking the cooling system's effect need to be done to check whether heat sink meets the thermal design requirement. Using this method described in this paper, the loss curves in different working conditions and considering the influence of temperature are obtained.

\section{References}

1. Chang $\mathrm{Y}$ J, Wang $\mathrm{C}$ C. A generalized heat transfercorrelation for louver fingeometry [J]. InternationalJournal of Heat and Mass Transfer, 1997,40 (3):533-544.

2. J. Y. Wang, W. R. Zhong, W, J, Wu, "Research for Improving High Power Anti-explosion Inverter 's Cooling Performance," Xi'an: Journal of Xi'an polytechnic university, 2006, vol. 1, pp. 42-45.

3. Masud Behnia, David Copeland, Denpong Soodphakdee. A Comparison of Heat Sink Geometries for Laminar Forced Convection:Numerical Simulation of Periodically Developed Flow [C] 1998 Inter Society Conference on Thermal Phenomena, 310 - 315.

4. Dvinsky A, BarCohen A, Strelets.Thermal fluidAnalysis ofStaggered and Inline Pin Fin sinks[C] 2000 Inter Society Conference on Thermal Phenomena, 157- 164.

5. Wieting A R. Empirical correlations for heat transfer and flow friction characteristics of rectangularoffsetfin heat exchangers[J]. Heat Transfer,1997(3): 488-490.

6. Manglik R M, Bergles AE. Heat transfer and pressure drop correlations for the rectangular offset stripfin compact heat exchangers[J]. Exp Thermal andFluid Sci, 1995,10: 171-180.

7. Ren $\mathrm{N}, \mathrm{Gu}$ B. Experimental study and numericalsimulation of heat and mass transfer on plain fin inwet conditions $[\mathrm{J}]$. Journal of Chemical Industry andEngineering , 2007, 58( 7) : 16261 631.

8. PHILIPS A M, JANKOVIC M, BAILEY $\mathrm{K}$, Development issues of an ISG PM machine and control system $[\mathrm{C}] 7^{\text {th }}$ international Conference on Power Electronics, Oct. 22-26,2007,Daegu, Korea. 2007:922-929.

9. Flannery J, Cheasty P, Meinhardt M, Present practice of power packaging for DC/DC converters $[\mathrm{J}]$ Integrated Power Packaging, 2000(7):3-7.

10. Darbandi M, Naderi A. Multiblock hybrid gridfinite volume method to solve flow in 
irregulargeometries[J]. Computer Methods in AppliedMechanics and Engineering, 2006,196(1/3):321-336.

11. DE Backer J W, Vos W G, Germonpre P,Flow analyses in the lower airways:patientspecificmodel and boundary conditions[J]. Medical Engineeringand Physics, 2008,30(7): 872-879.

12. Jafaria, Tynjala T, Mousavis M, Simulation of heat transfer in aferrofluid usingcomputational fluid dynamics technique[ J] .Inter national Journal of $\mathrm{H}$ eat and Fluid Flow, 2008,29(4) : 11971202.
13. Tsuji T, Kajitani T,Nishino T. Heat transferenhancement in a turbulent natural convection boundarylayer along a vertical flat plate $[\mathrm{J}]$. International Journalof Heat and Fluid Flow, 2007, 28( 6): 1472-1483.

14. Thoben M, Mainka K, Bayerer R, Fromvehicle drive cycle to reliability testing of powermodules for hybrid vehicle inverter [C] PCIM Europe2008: International Exhibition \& Conference for PowerElectronics Intelligent Motion Power Quality, May $27-$ 29,2008,Nuremberg,GermanyIEEE,2008:651-656. 